\title{
Performance of a predatory ladybird beetle, Anegleis cardoni (Coleoptera: Coccinellidae) on three aphid species
}

\author{
OMKAR, GYANENDRA KUMAR and JYOTSNA SAHU \\ Ladybird Research Laboratory, Department of Zoology, University of Lucknow, Lucknow 226007, India; \\ e-mail: omkaar55@hotmail.com
}

Key words. Coccinellidae, Anegleis cardoni, prey, Aphis gossypii, Aphis craccivora, Lipaphis erysimi, reproduction, life table, fitness

\begin{abstract}
Qualitative and quantitative differences in prey are known to affect the life histories of predators. A laboratory study was used to evaluate the suitability of three aphid prey, Aphis gossypii, Aphis craccivora and Lipaphis erysimi, for the ladybird beetle, Anegleis cardoni (Weise). Development was fastest on A. gossypii followed by A. craccivora and L. erysimi. Percentage pupation, immature survival, adult weight and the growth index were all highest when reared on $A$. gossypii and lowest on L. erysimi. Similarly, oviposition period, lifetime fecundity and egg viability were all highest on a diet of $A$. gossypii, lowest on L. erysimi and intermediate on A. craccivora. Age-specific fecundity functions were parabolic. Adult longevity, reproductive rate and intrinsic rate of increase were all highest on $A$. gossypii and lowest on $L$. erysimi. Life table parameters reflected the good performance on $A$. gossypii and poor performance on L. erysimi. Estimates of individual fitness values for the adults reared on A. gossypii and A. craccivora were similar and higher than that of adults reared on $L$. erysimi. Thus, the three species of aphid can all be considered essential prey for $A$. cardoni.
\end{abstract}

\section{INTRODUCTION}

Food quality can influence many aspects of the development, survival and reproduction of predators. In order to understand the behaviour, biology and ecology of insects and develop pest management strategies it is important to have a good knowledge of the ways insects interact with their food sources. Ladybird beetles are predators of aphids, mealybugs, scale insects, whiteflies, thrips, mites and a number of other pest species (Hodek, 1996; Dixon, 2000). However, some ladybirds are generalists and others specialists (Hodek, 1996). Studies on prey suitability can increase our understanding of the feeding preferences and prey specificity of ladybirds.

Although the suitability of prey for ladybird beetles is well studied (reviewed in Hodek, 1996) the importance of the subject remains undiminished (Michaud, 2000, 2005; Kalaskar \& Evans, 2001; Nielsen et al., 2002). Both larvae and adults of the majority of the species of coccinellid are predators. Most coccinellid predators survive on a "mixed diet" composed of "essential" and "alternative" prey (Hauge et al., 1998; Evans et al., 1999; Nielsen et al., 2002). Essential prey supports development and reproduction, whereas alternative prey enables adults to survive when essential prey is scarce (Hodek, 1962; Mills, 1981; Evans et al., 1999). Dixon (2000) distinguished "nursery" prey as the prey selected by ovipositing females for their immature stages. The range of nursery prey is more limited than that of the adults. Malcolm (1992) proposed "included", "peripheral" and "excluded" as alternatives to essential, alternative and rejected prey, respectively. Based on larval performance Michaud (2005) categorized prey suitability as either "optimal", "adequate" or "marginal". In general, the growth, survival and reproduction of the predator are best when it is reared on essential prey. Rana et al. (2002) suggested that the performance of a ladybird can be improved by selection, even if the prey is initially less suitable.

Apart from nutritional quality, numerous factors, viz. prey defense mechanisms (Dixon, 1958, 2000; Arakaki, 1989), plant architecture (Carter et al., 1984; Rott \& Ponsonby, 1992; Vohland, 1996; Clark \& Messina, 1998), etc. can further influence prey suitability. Though laboratory studies rarely include all these aspects, they can provide an indication of prey preference and nutritional quality.

The suitability of a species of prey can be assessed by evaluating the effect feeding on it has on the life history attributes of the predator, namely development, survival, adult weight and reproduction. Kalushkov \& Hodek (2001) suggest that quantitative data on a predator's rate of development, survival and reproduction indicate the adequacy of the prey. The influence of food quality on growth, development and reproductive success is well studied (Gilbert \& Owen, 1990; Francis et al., 2000; Bilde \& Toft, 2001; Stamp \& Meyerhoefer, 2004; Ishiguri \& Toyoshima, 2006). Reproduction requires high-energy resources that are supplied by food, which is a major regulatory factor of reproductive success (Houck, 1991).

Owing to their economic and biological importance, prey-dependent responses have been evaluated for a number of ladybird beetles, viz. Propylea quatuordecimpunctata L. (Baumgartner et al., 1987), Adalia bipunctata (Kalushkov, 1998), Coccinella septempunctata Linnaeus 
(Omkar \& Srivastava, 2003; Kalushkov \& Hodek, 2004), Coccinella transversalis Fabricius (Babu, 1999; Omkar \& James, 2004), Cheilomenes sexmaculata (Fabricius) (Suguira \& Takada, 1998; Bind \& Omkar, 2004), Propylea japonica Thunberg (Hukusima \& Komada, 1972; Kawauchi, 1981), Propylea dissecta (Mulsant) (Omkar \& Mishra, 2005), Scymnus frontalis Fabricius (Gibson et al., 1992), Coelophora biplagiata (Swartz) (Omkar et al., 2005), Micraspis discolor (Fabricius) (Omkar, 2006) and many more.

Anegleis cardoni (Weise) (Tribe: Coccinellini) is an attractively patterned, medium-sized ladybird beetle, which occurs in southern and northern parts of India (Puttarudriah \& Channabasavanna, 1953; Ghorpade, 1979). Kapur (1972) and Omkar \& Bind (1993) reported A. cardoni from Goa and Lucknow, respectively. Anegleis cardoni is reported to be a voracious feeder on whiteflies (Sternorrhyncha: Aleyrodidae) (Ramani et al., 2002) and scale insect pests (Sternorrhyncha: Coccidae) of sandalwood (Sundararaj, 2008). Both larvae and adults of $A$. cardoni feed on various aphid species, viz. Aphis gossypii Glover on Solanum melongena Linnaeus, Brevicoryne brasssicae Linnaeus on Brassica oleracae Linnaeus, Macrosiphum miscanthi (Takahashi) on Triticum aestivum Linnaeus and M. pisi Kaltenbach on Pisum sativum Linnaeus (Afroze, 2000). It is also a predator of Aphis craccivora Koch, Lipaphis erysimi (Kaltenbach), Uroleucon compositae Theobald, Myzus persicae Sulzer, Acyrthosiphon pisum (Harris) and many other species of aphids (Aphids of Karnataka; http://www.aphidweb. com). The objective of the present study was to determine the larval performance of $A$. cardoni on three common species of aphid in order to assess their suitability as prey for this ladybird.

\section{MATERIAL AND METHODS}

\section{Laboratory maintenance}

To establish a stock culture, adults and different life stages (eggs, larvae and pupae) of A. cardoni were collected from Ashoka (Polyalthia longifolia) trees, located within the campus of the University of Lucknow, India $\left(26^{\circ} 50^{\prime} \mathrm{N}, 80^{\circ} 54^{\prime} \mathrm{E}\right)$ Mating pairs and different life stages were kept in Petri dishes $(9.0 \times 1.5 \mathrm{~cm})$ in an Environmental Test Chamber (ETC) at $27 \pm$ $2^{\circ} \mathrm{C} ; 65 \pm 5 \% \mathrm{RH}$; and a $14 \mathrm{~L}$ : $10 \mathrm{D}$ photoperiod and were supplied with one of the following aphid species: Aphis craccivora reared on bean (Dolichos lablab Linnaeus), Aphis gossypii reared on bottle gourd (Lagenaria vulgaris Seringe) or Lipaphis erysimi reared on mustard (Brassica campestris Linnaeus). The aphid supply was replenished every $24 \mathrm{~h}$. Oviposition was monitored twice daily and eggs removed with the help of a fine camel hair brush and placed into Petri dishes. The numbers of eggs that hatched were recorded. Larvae were reared on the same species of aphids in plastic beakers $(9.5 \times 6.5 \mathrm{~cm})$ until they pupated. The freshly emerged adults were paired for mating, fed on the same species of aphid and the eggs they laid were removed.

\section{Experimental design}

Immature development and survival

To evaluate larval performance in terms of development and survival, one hundred eggs were collected from the stock culture and placed in Petri dishes. The incubation period and number of eggs that hatched were recorded. Hatchling first instar larvae were transferred to glass beakers (as above), five per beaker. Larvae were provided with the same species of aphid as their parents together with a twig or leaf of the aphid's host plant. The supply of aphids was refreshed every $24 \mathrm{~h}$. The experiment was replicated ten times; the five larvae in each beaker constituting a replicate. The number of larvae surviving to the adult stage and the duration of each instar were recorded. The duration of the pre-pupal and pupal periods were also recorded. Fresh weights of adults were recorded within twenty four hours of emergence. Total developmental period (egg to adult), percentage pupation (no. of pupae / no. of first instars $\times 100$ ), percentage immature survival (no. of adults emerged / no. of first instars $\times 100$ ), growth index (percentage pupation / mean larval duration) and sex ratio (number of females / total adult emergence) were recorded.

\section{Reproduction}

Ten pairs of newly emerged adults $(\mathrm{n}=10)$ were isolated in Petri dishes (as above) and provided with either fresh A. craccivora on D. lablab leaves, A. gossypii on L. vulgaris or L. erysimi on $B$. campestris. Aphids and leaves were replaced every $24 \mathrm{~h}$. Oviposition and egg viability were recorded daily for each female over her entire reproductive life. In addition to the longevity of males and females, the pre-oviposition period (time from emergence until first oviposition), oviposition period (time from first to last day of oviposition), post-oviposition period (time from the last oviposition until death) reproductive rate (fecundity/oviposition period) and day of peak oviposition were recorded. Age-specific fecundity graphs for the ladybirds fed on each of the aphid species are presented.

\section{Data analysis}

The results were subjected to a one-way ANOVA and means were compared using Tukey's HSD test with $\alpha=0.05$ (MINITAB 2003). Pearson's correlation coefficient was used to test for correlations between female weight and longevity, fecundity, pre-oviposition, oviposition and post oviposition periods, and between male weight and egg fertility. If significant the results were subjected to a regression analysis in order to obtain the best relationship.

\section{Life table parameters}

Life table parameters for this ladybird when reared on each of the three prey species were calculated following Birch (1948):

Net reproductive rate $(\mathrm{Ro})=\Sigma 1 \mathrm{xMx}$.

Mean generation time $(\mathrm{Tc})=\Sigma 1 \mathrm{xMx} /$ Ro (where, $\mathrm{x}=$ pivotal age).

$1 \mathrm{x}=$ number of females surviving in a given population $(\mathrm{n}=10)$.

$\mathrm{Mx}=$ net fecundity of emerging female.

Intrinsic rate of increase $\left(\mathrm{r}_{\mathrm{m}}\right)=\ln \mathrm{Ro} / \mathrm{Tc}$

The finite rate of increase $\left(\lambda_{\mathrm{m}}\right)=\operatorname{antilog} \mathrm{e}^{-\mathrm{r}_{\mathrm{m}}}$ (where $\mathrm{e}=$ 2.718228).

Generation time $(\mathrm{GT})=\ln \mathrm{Ro} / \mathrm{r}_{\mathrm{m}}$.

Doubling time $(\mathrm{DT})=\ln 2 / \mathrm{r}_{\mathrm{m}}$.

\section{Individual female fitness}

The performance of an insect reared under standard conditions is perhaps best described by an overall measure of individual fitness. McGraw \& Caswell (1996) use the following equation to estimate individual fitness $(\mathrm{R})$ from life history data:

$\mathrm{R}=\{\ln (\mathrm{mV})\} / \mathrm{D}$, where $\mathrm{m}=\operatorname{survival}(1$ or 0$)$.

$\mathrm{V}=$ potential fecundity.

$\mathrm{D}=$ total development time. 
TABLE 1. Mean ( \pm S.E.) duration (days) of each stage in the development of $A$. cardoni recorded when reared on one of three aphid species $(\mathrm{df}=2,42)$. Means within rows with the same letter were not significantly different $(\alpha>0.05)$.

\begin{tabular}{lccccc}
\hline \multirow{2}{*}{ Stage } & \multicolumn{3}{c}{ Aphid species } \\
\cline { 2 - 6 } & A. gossypii & A. craccivora & L. erysimi & F value & P value \\
\hline Incubation period & $4.07 \pm 0.12 \mathrm{a}$ & $4.27 \pm 0.12 \mathrm{a}$ & $4.40 \pm 0.13 \mathrm{a}$ & 1.87 & 0.166 \\
First instar & $2.75 \pm 0.08 \mathrm{a}$ & $3.20 \pm 0.08 \mathrm{a}$ & $3.87 \pm 0.05 \mathrm{~b}$ & 62.28 & 0.000 \\
Second instar & $3.32 \pm 0.13 \mathrm{a}$ & $4.03 \pm 0.08 \mathrm{~b}$ & $3.92 \pm 0.05 \mathrm{~b}$ & 17.67 & 0.000 \\
Third instar & $3.82 \pm 0.17 \mathrm{a}$ & $4.60 \pm 0.12 \mathrm{~b}$ & $4.67 \pm 0.12 \mathrm{~b}$ & 11.66 & 0.000 \\
Fourth instar & $4.71 \pm 0.13 \mathrm{a}$ & $5.34 \pm 0.13 \mathrm{ab}$ & $5.85 \pm 0.14 \mathrm{~b}$ & 18.26 & 0.000 \\
Pre-pupa & $1.84 \pm 0.05 \mathrm{a}$ & $1.91 \pm 0.03 \mathrm{a}$ & $2.04 \pm 0.03 \mathrm{~b}$ & 7.93 & 0.001 \\
Pupa & $5.21 \pm 0.12 \mathrm{a}$ & $5.40 \pm 0.11 \mathrm{ab}$ & $5.90 \pm 0.11 \mathrm{~b}$ & 7.74 & 0.001 \\
Total development & $25.71 \pm 0.25 \mathrm{a}$ & $28.75 \pm 0.27 \mathrm{~b}$ & $30.56 \pm 0.21 \mathrm{c}$ & 101.65 & 0.000 \\
\hline
\end{tabular}

TABLE 2. Mean developmental parameters of $A$. cardoni when reared on one of three aphid species $(\mathrm{df}=2,42)$. Means within rows with the same letter were not significantly different $(\alpha>0.05)$.

\begin{tabular}{lccccc}
\hline Aphid species & A. gossypii & A. craccivora & L. erysimi & F value & P value \\
\hline Immature survival (\%) & $88.46 \pm 2.46 \mathrm{a}$ & $84.00 \pm 3.49 \mathrm{a}$ & $75.00 \pm 4.45 \mathrm{a}$ & 3.93 & 0.027 \\
Pupation (\%) & $89.78 \pm 2.49 \mathrm{a}$ & $86.67 \pm 3.74 \mathrm{a}$ & $79.67 \pm 3.17 \mathrm{a}$ & 2.75 & 0.075 \\
Growth index & $4.59 \pm 0.25 \mathrm{~b}$ & $3.49 \pm 0.21 \mathrm{ab}$ & $2.48 \pm 0.19 \mathrm{a}$ & 23.02 & 0.000 \\
Male wt (mg) & $6.81 \pm 0.13 \mathrm{~b}$ & $6.13 \pm 0.13 \mathrm{c}$ & $5.04 \pm 0.14 \mathrm{a}$ & 44.56 & 0.000 \\
Female wt (mg) & $7.91 \pm 0.17 \mathrm{~b}$ & $7.16 \pm 0.20 \mathrm{c}$ & $5.85 \pm 0.19 \mathrm{a}$ & 31.20 & 0.000 \\
Sex ratio & $0.55 \pm 0.03 \mathrm{a}$ & $0.55 \pm 0.06 \mathrm{a}$ & $0.47 \pm 0.06 \mathrm{a}$ & 0.96 & 0.392 \\
\hline
\end{tabular}

Individual fitness measures were calculated for females reared on all three species of aphids and then subjected to a one-way ANOVA followed by Tukey's HSD test with $\alpha=0.05$.

\section{RESULTS}

\section{Immature development and survival}

The duration of the various life stages of $A$. cardoni reared on each of the three aphid diets varied significantly (Table 1). Incubation time and total developmental period of $A$. cardoni were shortest when fed on $A$. gossypii and longest on $L$. erysimi. Total larval development was significantly shorter on A. gossypii than on L. erysimi and the total developmental period on each of the three species of aphid differed significantly. Mean weights of both males and females were lower when reared on L. erysimi compared to the other two aphid species (Table 2). The growth index and survival from egg hatch to adult emergence were highest on A. gossypii and lowest on L. ery- simi. There were no significant differences in sex ratio of A. cardoni reared on three aphid species.

\section{Reproduction}

There were no significant differences between the treatments in either the pre-oviposition or post-oviposition periods of $A$. cardoni females, but the oviposition period was significantly longer and the reproductive rate higher on A. gossypii and A. craccivora than on L. erysimi (Table 3 ). Lifetime fecundity was highest on $A$. gossypii, lowest on $L$. erysimi and intermediate on $A$. craccivora. Percentage egg viability was lower on $L$. erysimi than on either A. gossypii or A. craccivora.

In all three treatments the age-specific fecundity function was parabolic. The oviposition rate increased with reproductive age up to a peak followed by a gradual decline (Fig. 1). Female age at peak oviposition also differed among treatments, occurring earlier on $A$. craccivora than on either A. gossypii or L. erysimi (Table 3).

TABle 3. Mean ( $\pm \mathrm{SE})$ reproductive data for $A$. cardoni females $(\mathrm{n}=10$ per treatment) when fed on one of three aphid species (df $=2,27)$. Means within rows with the same letter were not significantly different $(\alpha>0.05)$.

\begin{tabular}{lccrrr}
\hline \multirow{2}{*}{ Life history parameters } & \multicolumn{3}{c}{ Aphid species } & \multirow{2}{*}{ F value } & \multirow{2}{*}{ P value } \\
\cline { 2 - 4 } & \multicolumn{1}{c}{ A.gossypii } & A. craccivora & L. erysimi & & 0.201 \\
Pre-oviposition period (days) & $2.00 \pm 0.39 \mathrm{a}$ & $2.6 \pm 0.40 \mathrm{a}$ & $2.90 \pm 0.23 \mathrm{a}$ & 1.70 & 0.000 \\
Oviposition period (days) & $58.30 \pm 1.67 \mathrm{~b}$ & $52.1 \pm 1.59 \mathrm{~b}$ & $27.00 \pm 1.76 \mathrm{a}$ & 97.97 & 0.09 \\
Post-oviposition period (days) & $5.80 \pm 0.49 \mathrm{a}$ & $6.60 \pm 0.56 \mathrm{a}$ & $3.70 \pm 1.27 \mathrm{a}$ & 3.09 & 0.062 \\
Lifetime fecundity (eggs) & $397.00 \pm 10.84 \mathrm{c}$ & $327.70 \pm 14.81 \mathrm{~b}$ & $136.60 \pm 10.13 \mathrm{a}$ & 124.19 & 0.000 \\
Egg viability (\%) & $78.00 \pm 1.60 \mathrm{~b}$ & $73.85 \pm 0.73 \mathrm{~b}$ & $61.86 \pm 1.22 \mathrm{a}$ & 45.98 & 0.000 \\
Female age at peak oviposition (days) & $29.30 \pm 0.78 \mathrm{c}$ & $23.90 \pm 1.06 \mathrm{~b}$ & $18.3 \pm 1.10 \mathrm{a}$ & 31.05 & 0.000 \\
Peak oviposition rate (eggs/day) & $22.70 \pm 0.40 \mathrm{~b}$ & $21.5 \pm 0.40 \mathrm{~b}$ & $17.3 \pm 0.52 \mathrm{a}$ & 41.19 & 0.000 \\
Adult longevity (days) & $75.70 \pm 1.55 \mathrm{c}$ & $68.60 \pm 1.55 \mathrm{~b}$ & $43.95 \pm 1.47 \mathrm{a}$ & 124.44 & 0.000 \\
Mean reproductive rate (eggs/day) & $6.81 \pm 0.06 \mathrm{~b}$ & $6.28 \pm 0.16 \mathrm{~b}$ & $5.07 \pm 0.20 \mathrm{a}$ & 33.97 & 0.000 \\
Individual fitness & $0.23 \pm 0.002 \mathrm{c}$ & $0.23 \pm 0.002 \mathrm{~b}$ & $0.15 \pm 0.003 \mathrm{a}$ & 201.03 & 0.000 \\
\hline
\end{tabular}




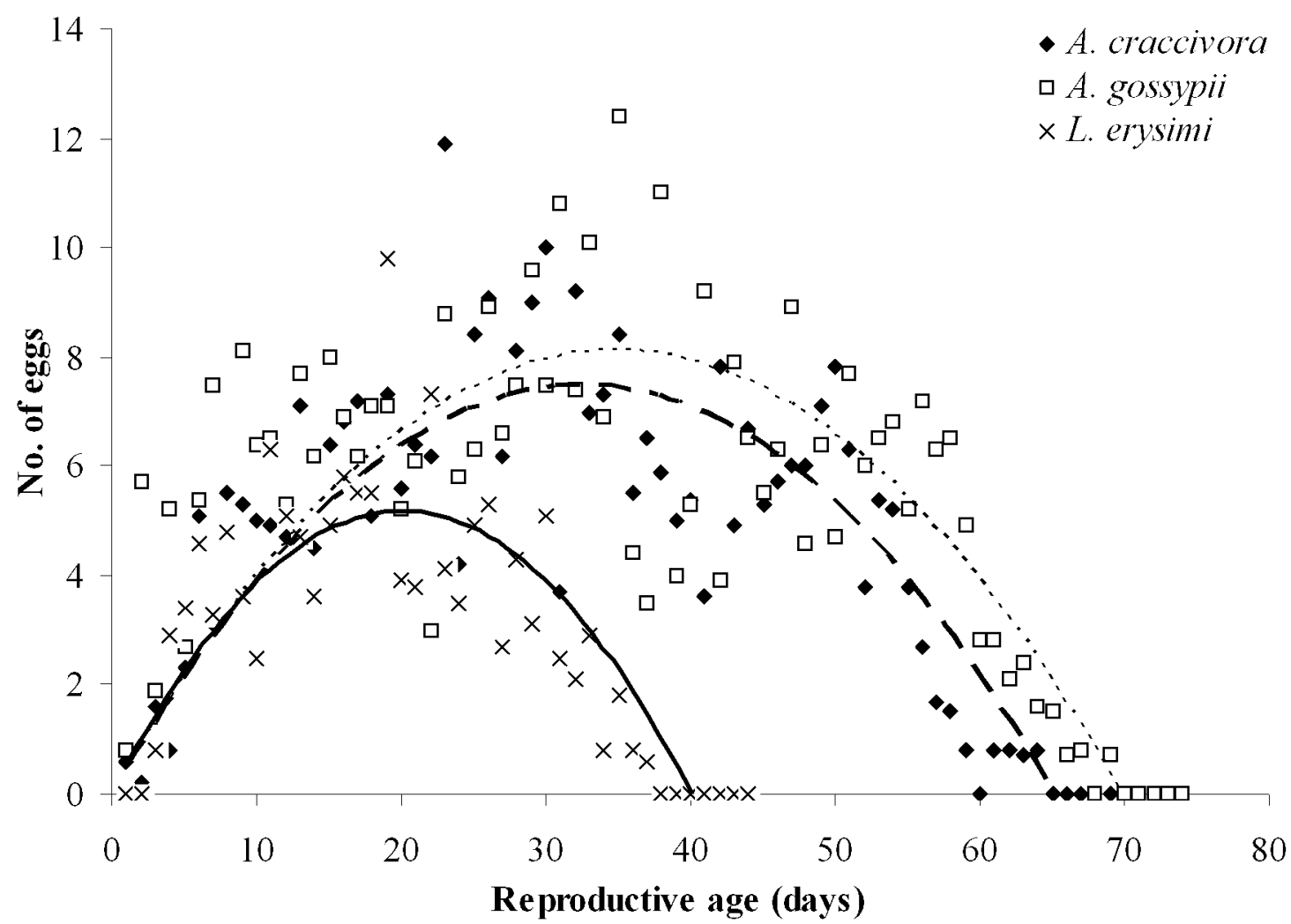

Fig. 1. Age specific fecundity of $A$. cardoni when fed on one of three aphid species. The thick dashed line is the fecundity curve when fed A. craccivora, the dashed line A. gossypii and thick solid line L. erysimi.

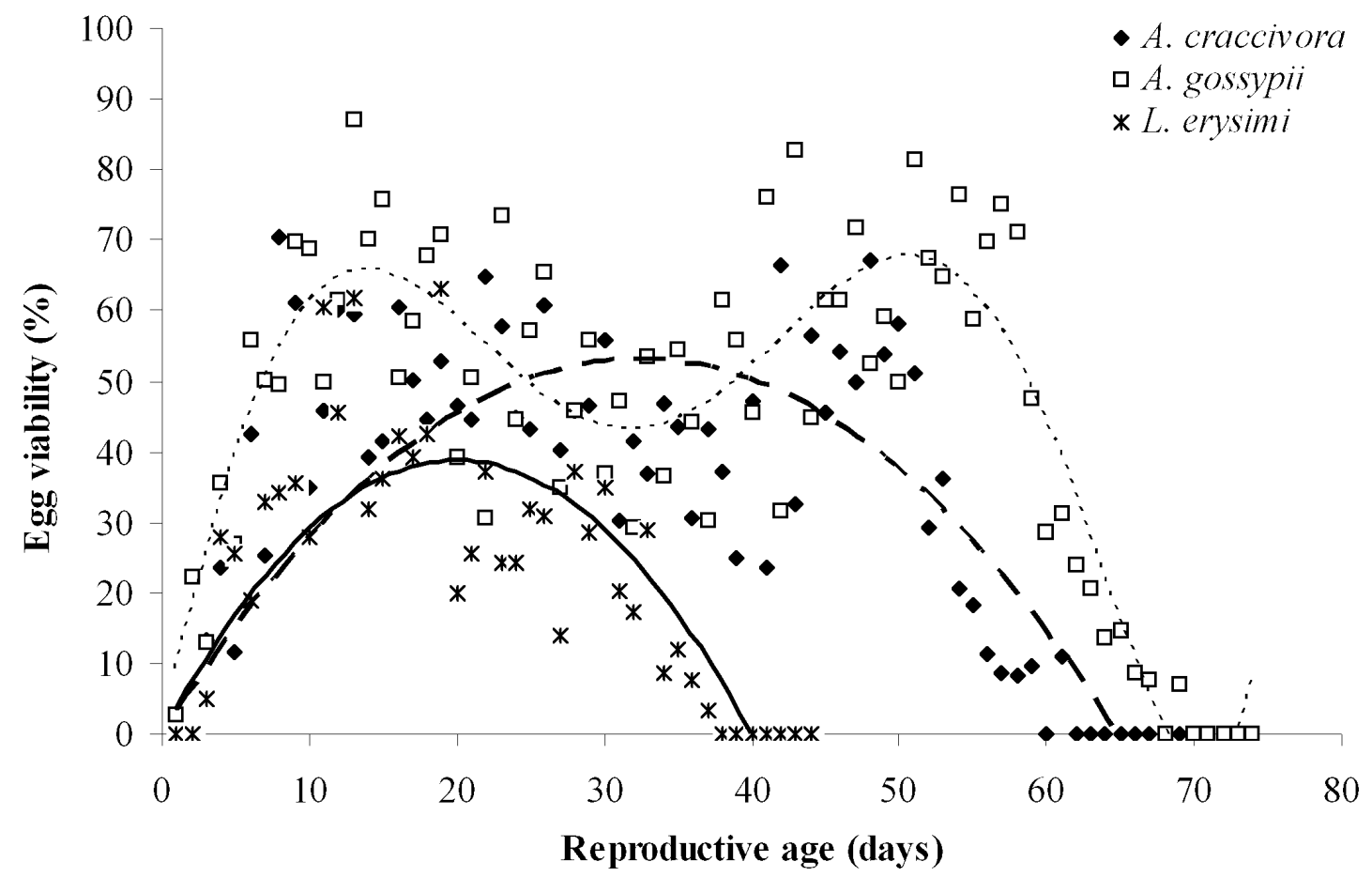

Fig. 2. Age specific egg viability of $A$. cardoni when fed on one of three aphid species. The thick dashed line is the egg viability curve when fed A. craccivora, the dashed line A. gossypii and thick solid line L. erysimi.

Individual comparison of means revealed that the peak oviposition rate of $A$. cardoni fed on $L$. erysimi differed significantly from that when fed on $A$. gossypii or $A$. craccivora, and was highest on $A$. gossypii and $L$. erysimi. Age-specific fertility showed trends similar to those for fecundity except $A$. gossypii where it was bimodal (Fig. 2). The longevity of males of $A$. cardoni was not significantly different from that of the females $(\mathrm{F}$ 
TABLE 4. Regression equations of the relationship between various reproductive attributes (Y) and adult weight (X).

\begin{tabular}{lccccc}
\hline Relationship & Regression equation & $\mathrm{r}^{2}$ & F value & df & P value \\
\hline Pre-oviposition period and female wt. & $\mathrm{Y}=-0.199 \mathrm{X}+3.89$ & 0.000 & 0.95 & 1,28 & 0.337 \\
Oviposition period and female wt. & $\mathrm{Y}=11.4 \mathrm{X}-33.6$ & 0.632 & 50.86 & 1,28 & 0.000 \\
Post-oviposition period and female wt. & $\mathrm{Y}=1.00 \mathrm{X}-1.62$ & 0.090 & 4.17 & 1,28 & 0.051 \\
Fecundity and female wt. & $\mathrm{Y}=-24.5 \mathrm{X}^{3}+492 \mathrm{X}^{2}-3146 \mathrm{X}+6609$ & 0.723 & 26.28 & 3,26 & 0.000 \\
Female longevity and female wt. & $\mathrm{Y}=-2.63 \mathrm{X}^{3}+51.9 \mathrm{X}^{2}-323 \mathrm{X}+688$ & 0.667 & 20.40 & 3,26 & 0.000 \\
Fertility and male wt. & $\mathrm{Y}=8.24 \mathrm{X}+21.8$ & 0.766 & 96.14 & 1,28 & 0.000 \\
\hline
\end{tabular}

$\mathrm{df}=$ degree of freedom, $\mathrm{r}^{2}=$ regression coefficient.

TABLE 5. Demographic parameters of $A$. cardoni reared and maintained on one of three aphid species.

\begin{tabular}{lccccc}
\hline Aphid prey & $\mathrm{R}_{0}$ & $\mathrm{r}_{\mathrm{m}}$ & $\mathrm{Tc}$ & $\mathrm{DT}(\mathrm{d})$ & $\lambda$ \\
\hline A. gossypii & 226.3 & 0.13 & 42.2 & 2.75 & 1.14 \\
A. craccivora & 167.1 & 0.12 & 42.7 & 2.81 & 1.13 \\
L. erysimi & 65.6 & 0.07 & 56.0 & 3.29 & 1.08 \\
\hline
\end{tabular}

$=2.36, \mathrm{P}=0.130, \mathrm{df}=1,58)$. However, there was a significant effect of aphid species on pooled adult longevity (Table 3 ). Longevity of A. cardoni was shorter on L. erysimi than on the other two aphid species. The individual fitness values of the beetles reared on each of the three aphid diets differed significantly, being highest on $A$. gossypii, lowest on L. erysimi and intermediate on $A$. craccivora (Table 3 ).

Female weight was positively correlated with the length of the oviposition $(\mathrm{r}=0.803, \mathrm{P}=0.000)$ and postoviposition periods $(\mathrm{r}=0.360, \mathrm{P}=0.051)$, fecundity $(\mathrm{r}=$ $0.834, \mathrm{P}=0.000)$ and longevity $(\mathrm{r}=0.806, \mathrm{P}=0.000)$, but not the pre-oviposition period $(\mathrm{r}=-0.181, \mathrm{P}=0.337)$. Male weight was also strongly positively correlated with fertility $(r=0.880, P=0.000)$. These positive correlations were further substantiated by statistically significant linear regressions (Table 4) for all relationships except that between female weight and longevity, and female weight and fecundity, which were best fitted by S-shaped curves produced by third degree polynomial equations. Regression analysis revealed that fecundity and longevity were not correlated with female weight. Female weight also did not correlate with the length of the preoviposition period or post-oviposition period, which is supported by non-significant linear regressions.

\section{Life table parameters}

The net reproductive rate $\left(\mathrm{R}_{0}\right)$, intrinsic rate of increase $\left(\mathrm{r}_{\mathrm{m}}\right)$ and finite rate of increase $(\lambda)$ were highest when maintained on a diet of $A$. gossypii and lowest on a diet of L. erysimi (Table 5). Mean generation and doubling times were lowest on A. gossypii and highest on L. erysimi.

\section{DISCUSSION}

The present study reveals a significant influence of aphid prey on the life attributes of $A$. cardoni, with overall best performance on A. gossypii. The shorter developmental period on $A$. gossypii than on $A$. craccivora and $L$. erysimi indicates that $A$. gossypii was the most suitable prey for larval development, probably due to the presence of the nutrients essential for growth and development. The higher immature survival and adult emergence on A. gossypii and A. craccivora compared to L. erysimi indicates the lower suitability of the latter prey species.

The suitability of $A$. gossypii and A. craccivora for $A$. cardoni suggests that these aphids do not sequester toxic chemicals from their host plants, L. vulgaris and $D$. lablab. Many studies have reported $A$. craccivora as an essential prey for ladybird beetles, viz. C. septempunctata (Hodek, 1960), P. dissecta (Omkar \& Mishra, 2005) and C. sexmaculata (Omkar \& Bind, 2004), but A. craccivora fed on Robinia pseudoacacia L. (Fabales: Fabacae) was found to be toxic to Harmonia axyridis, due to the presence of the amines, canavanine and ethanolamine sequestered from the host plant (Obatake \& Suzuki, 1985). So what constitutes suitable prey varies among ladybird species, e.g. A. gossypii is suitable for C. sexmaculata (George, 1999) but less so for C. septempunctata (Zalavadia \& Kapadia, 2000). Myzus persicae is suitable for C. undecimpunctata (Karaman et al., 1998) but less so for C. septempunctata (Lakhanpal \& Raj, 1998).

Differential consumption can play a role in influencing reproductive attributes and may have been partly responsible for the reduced reproductive performance of $A$. cardoni on L. erysimi. Since adults were fed the same prey as larvae the observed reproductive performance reflects the sum effect of prey species on both immature development and subsequent adult reproduction. The shorter longevity of A. cardoni reared on L. erysimi relative to other diets, suggests the possible presence of chemicals or alkaloids (Hodek, 1956; Okamoto, 1966) that make this prey unsuitable for this ladybeetle. Lipaphis erysimi has a pungent smell, presumably the result of compounds sequestered from its host plant, and it is possible that allyl isothiocyanates sequestered from its host plant are, to some degree, responsible for its reduced suitability as prey, as previously reported for other Coleoptera (Williams et al., 1993; Noble et al., 2002). C. septempunctata also develops more slowly when reared on L. erysimi (Singh et al., 1994; Kumar \& Verma, 1996; Joshi et al., 1999). On the other hand C. septempunctata (Ali \& Rizvi, 
2007), C. transversalis (Omkar \& James, 2004) and $P$. dissecta (Pervez \& Omkar, 2004) perform relatively better on L. erysimi in terms of development, survival and reproduction.

Females fed on $A$. gossypii were more fecund than those fed on either A. craccivora or L. erysimi, again reflecting the nutritive value and palatability of the former species. The low fecundity recorded when fed on L. erysimi is most likely due in part to the small size of the ladybirds reared on this diet and to the prey's effect on egg maturation. Coccinellids fed on prey of high quality have more ovarioles and mature them earlier than those fed on poor quality prey (Rhamalinghan, 1986). In case of Brachinus lateralis (Coleoptera: Carabidae), Juliano (1985) reports that the consumption of high quality prey results in faster development, larger food reserves and a larger body size. An interesting aspect of the current study is that the daily fecundity ranged between 1-24 eggs /day. Afroze (2000) reports a slightly higher fecundity range of 8-36 eggs / day for this ladybird fed on $B$. brassicae. It is important to determine the reasons for the low fecundity recorded in this study. A strong positive correlation between fecundity and weight was recorded in this study. This, as postulated by Dixon \& Guo (1993), may be due to the higher number of ovarioles in large females. Hippodamia convergens however, does not show the same trend between ovariole number and size (Michaud \& Quereshi, 2006). Dixon \& Guo (1993) also suggest that although fecundity was associated with size of the females the availability of food might have a greater effect. The higher percentage egg viability of the ladybirds fed on $A$. gossypii may partly be ascribed to an acceleration in spermatogenesis and increase sperm survival (Ponsonby \& Copland, 1998).

Like other ladybirds, A. cardoni females exhibit a triangular fecundity function, i.e. daily oviposition initially increases with age to a peak, then declines with age (Dixon \& Agarwala, 2002). The peak in oviposition occurs earlier in adult life under favourable conditions. Differences between the times of peak oviposition indicate the age-specific fecundity is prey-dependent, with a delayed peak indicating inferior prey quality. Females may delay ovipositing in the presence of less suitable prey or the time of peak oviposition may be determined by the rate of ovariole maturation. The greater longevity of ladybeetles fed A. gossypii may be attributed to the better nutritional resources provided by this prey.

The highest $\mathrm{R}_{0}, \mathrm{r}_{\mathrm{m}}$ and $\lambda$ values were recorded on a diet of $A$. gossypii, suggesting this aphid is suitable for mass rearing of $A$. cardoni. Birch (1948) pointed out that $\mathrm{r}_{\mathrm{m}}$ is influenced by age-specific survival and age-specific fecundity. In the present study, differences in the $\mathrm{r}_{\mathrm{m}}$ of $A$. cardoni were largely due to significant differences in reproductive rate.

Individual fitness values were significantly influenced by the prey species, as noted in other studies (Hemptinne et al., 1993; Evans et al., 1999; Soares et al., 2005; Omkar \& Mishra, 2005). The low fitness on L. erysimi was probably due to the delay in the onset in reproduction and low fecundity recorded when fed on this aphid. Low fitness in Gargaphia solani (Hemiptera: Tingidae) is also associated with a low fecundity and a delay in egg production to later in a female's life (Tallamy \& Denno, 1982).

This study reveals that all the species of aphids tested serve as essential prey for the predator $A$. cardoni and Aphis gossypii was the most suitable. The performance of $A$. cardoni was prey-dependent and the order of suitability of the prey tested was $A$. gossypii $>A$. craccivora $>$ L. erysimi.

\section{REFERENCES}

Afroze S. 2000: Bioecology of the coccinellid Anegleis cardoni (Weise) (Coleoptera: Coccinellidae), an important predators of aphids, coccids and pseudococcids. J. Entomol. Res. 24: $55-62$.

Ali A. \& Rizvi P.Q. 2007: Development and predatory performance of Coccinella septempunctata L. (Coleoptera: Coccinellidae) on different aphid species. J. Biol. Sci. 7: 1478-1483.

AraKaKi N. 1989: Alarm pheromone eliciting attack and escape responses in the sugar cane woolly aphid Ceratovacuna lanigera (Homoptera: Pemphigidae). J. Ethol. 7: 83.

BABU A. 1999: Influence of prey species on feeding preference, post-embryonic development of Coccinella transversalis $\mathrm{F}$. (Coleoptera: Coccinellidae). Entomon 24: 221-228.

Baumgartner J., Bieri M. \& Delucchi V. 1987: Growth and development of immature stages of Propylea 14-punctata L. and Coccinella septempunctata L. (Coleoptera: Coccinellidae) stimulated by the metabolic pool model. Entomophaga 32: 415-423.

Bilde T. \& Toft S. 2001: The value of three cereal aphid species as food for a generalist predator. Physiol. Entomol. 26: $58-68$.

BIND R.B. \& OMKAR 2004: Development and reproduction of Cheilomenes sexmaculata (Fabricius) (Coleoptera: Coccinellidae) on three aphid species. Insect Environ. 9(4): 149-150.

BIRCH L.C. 1948: The intrinsic rate of natural increase in insect populations. J. Anim. Ecol. 17: 15-26.

Carter M.C., Sutherland D. \& Dixon A.F.G. 1984: Plant structure and the searching efficiency of coccinellid larvae. Oecologia 63: 394-397.

Clark T.L. \& MESsina F.J. 1998: Plant architecture and foraging success of ladybird beetles attacking the Russian wheat aphid. Entomol. Exp. Appl. 86: 153-161.

Dixon A.F.G. 1958: The escape responses shown by certain aphids to the presence of the coccinellid Adalia decempunctata (L.) Trans. R. Entomol. Soc. Lond. 110: 319-334.

Dixon A.F.G. 2000: Insect Predator-Prey Dynamics, Ladybird Beetles and Biological Control. Cambridge University Press, Cambridge, $257 \mathrm{pp}$.

Dixon A.F.G. \& Agarwala B.K. 2002: Triangular fecundity function and ageing in ladybird beetles. Ecol. Entomol. 27: 433-440.

Dixon A.F.G. \& Guo Y. 1993: Egg and cluster size in ladybird beetles (Coleoptera: Coccinellidae): The direct and indirect effects of aphid abundance. Eur. J. Entomol. 90: 457-463.

Evans E.W., Stevenson A.T. \& Richards D.R. 1999: Essential versus alternatve foods of insect predators: benefits of a mixed diet. Oecologia 121: 107-112.

Francis F., Haubruge E., Defrance T. \& Gaspar C. 2000: Environmentally based maternal effect on reproduction of Adalia bipunctata: impact of aphid prey species. Med. Fac. Landbouww. Univ. Gent 65/2a: 303-310. 
George P.J.E. 1999: Prey preference of ladybeetle, Coccinella transversalis Fabricius (Coleoptera: Coccinellidae). Insect Environ. 5(2): 88.

GHorpade K.D. 1979: On some Coccinellidae (Coleoptera) attracted to light in India. Curr. Res. 8: 113-114.

Gibson R.L., Elliott N.C. \& Schaefer P. 1992: Life history and development of Scymnus frontalis F. (Coleoptera: Coccinellidae) on four species of aphid. J. Kans. Entomol. Soc. 65: $410-415$.

Gilbert F.S. \& Owen L. 1990: Size, shape, competition, and community structure in hoverflies (Diptera: Syrphidae). $J$. Anim. Ecol. 59: 21-39.

Hauge M.S., Nielsen F.H. \& Toft S. 1998: The influence of three cereal aphid species and mixed diet on larval survival, development and adult weight of Coccinella septempunctata Entomol. Exp. Appl. 89: 319-323.

Hemptinne J.L., Dixon A.F.G., Doucet J.L. \& Peterson J.E. 1993: Optimal foraging by hoverflies (Diptera: Syrphidae) and ladybirds (Coleoptera: Coccinellidae): Mechanisms. Eur. J. Entomol. 90: 141-150.

Hodek I. 1956: The influence of Aphis sambuci L. as prey of the ladybird beetle Coccinella septempunctata L. Věst. Čs. Spol. Zool. 20: 62-74.

Hodek I. 1960: The influence of various aphid species as food for two ladybirds Coccinella 7-punctata L. and Adalia bipunctata L. In: The Ontogeny of Insects. Proc. Symp. Praha 1959. Academia, Prague, pp. 314-316

Hodek I. 1962: Essential and alternative food in insects. In Strouhal H. \& Beier M. (eds): Transactions of the XIth International Congress of Entomology. Vol. 2. Organisationskomittee des XI Internationalen Kongress für Entomologie, Vienna, pp. 697-698.

HoDEK I. 1996: Food relationships. In Hodek I. \& Honěk A.: Ecology of Coccinellidae. Kluwer Academic Publishers, Dordrecht, Boston, London, pp. 143-238.

Houck M.A. 1991: Time and resource partitioning in Stethorus punctum (Coleoptera: Coccinellidae). Envir. Entomol. 20: 494-497.

Hukusima S. \& Komada M. 1972: Effect of several species of aphid as food on development and nutrition of Propylea japonica Thunberg (Coleoptera: Coccinellidae). Proc. Kansai Plant Prot. Soc. 14: 7-13.

Ishiguri Y. \& Toyoshima S. 2006: Larval survival and development of the peach fruit moth, Carposina sasakii (Lepidoptera: Carposinidae), in picked and unpicked apple fruits. Appl. Entomol. Zool. 41: 685-690.

Joshi S., Ballal C.R. \& RaO N.S. 1999: Biotic potential of three coccinellid predators on six different aphid hosts. $J$. Entomol. Res. 23: 1-7.

Juliano S.A. 1985: The effects of body size on mating and reproduction in Brachinus lateralis (Coleoptera: Carabidae). Ecol. Entomol. 10: 271-280.

Kalaskar A. \& Evans E.W. 2001: Larval responses of aphidophagous lady beetles (Coleoptera: Coccinellidae) to weevil larvae versus aphids as prey. Ann. Entomol. Soc. Am. 94: $76-81$.

KalushKov P.K. 1998: Ten aphid species (Sternorrhyncha: Aphididae) as prey for Adalia bipunctata (Coleoptera: Coccinellidae). Eur. J. Entomol. 95: 343-349.

Kalushrov P. \& HodeK I. 2001: New essential aphid prey for Anatis ocellata and Calvia quatuordecimguttata (Coleoptera: Coccinellidae). Biocont. Sci. Tech. 11: 35-39.

KalushKov P. \& Hodek I. 2004: The effect of thirteen species of aphids on some life history parameters of the ladybird Cocinella septempunctata. BioControl 49: 21-32.
KaPUR A.P. 1972: The Coccinellidae (Coleoptera) of Goa. Rec. Zool. Surv. India. 66: 309-320.

Karaman G., Makady M., Ali F. \& Hamouda S. 1998: Effect of feeding the ladybeetle Coccinella undecimpunctata aegyptiaca Reiche on different aphid species on fecundity and longevity of the adult stage. Arabian J. Plant Prot. 16: 3-6.

KAWAUCHI S. 1981: The number of oviposition, hatchability and the term of oviposition of Propylea japonica Thunberg (Coleoptera: Coccinellidae) under different food condition. Kontyu 49: 183-191.

Kumar D. \& Verma G.C. 1996: Studies of the biology of the various predators of mustard aphid, Lipaphis erysimi (Kalt.). J. Insect Sci. 9: 175-177.

LaKhanpal G.C. \& RaJ D. 1998: Predation potential of coccinellid and syrphid on important aphid species infesting rapeseed in Himachal Pradesh. J. Entomol. Res. 2: 181-190.

MaLcolm S.B. 1992: Prey defence and predator foraging. In Crawley M.J. (ed.): Natural Enemies: The Population Biology of Predators, Parasites and Diseases. Blackwell, Oxford, pp. 458-475.

McGraw J.B. \& Caswell H. 1996: Estimation of individual fitness level from life history data. Am. Nat. 147: 47-64.

Michaud J.P. 2000: Development and reproduction of ladybeetles (Coleoptera: Coccinellidae) on citrus aphids Aphis spiraecola Patch and Toxoptera citricida (Kirkaldy) (Homoptera: Aphididae). Biol. Contr. 18: 287-297.

Michaud J.P. 2005: On the assessment of prey suitability in aphidophagous Coccinellidae. Eur. J. Entomol. 102: 385-390.

Michaud J.P. \& Quereshi J.A. 2006: Reproductive diapause in Hippodamia convergens (Coleoptera: Coccinellidae) and its life history consequences. Biol. Contr. 39: 193-200.

Mills N.J. 1981: Essential and alternative foods for some British Coccinellidae (Coleoptera). Entomol. Gaz. 32: 197-202.

Nielsen F.H., Hauge M.S. \& Toft S. 2002: The influence of mixed aphid diets on larval performance of Coccinella septempunctata L. (Coleoptera: Coccinellidae). J. Appl. Entomol. 126: 194-197.

Noble R.R.P., Harvey S.G. \& Sams C.E. 2002: Toxicity of Indian mustard and allylisothiocyanate to masked chafer beetle larvae. Plant Health Progress, doi:10.1094/PHP-20020610-01-RS.

Oвatake H. \& SuzuKi H. 1985: On the isolation and identification of canavanine and ethanolamine contained in the black leaves of black locus, Robinia pseudoacacia, lethal for the ladybeetle Harmonia axyridis. Techn. Bull. Fac. Agr. Kagawa Univ. 36: 107-115.

Окамото Н. 1966: Three problems of prey specificity of aphidophagous coccinellids. In Hodek I. (ed.): Ecology of Aphidophagous Insects. Academia, Prague and Dr W. Junk, The Hague, pp. 45-46.

OMKAR 2006: Suitability of different foods for a generalist ladybird, Micraspis discolor (Coleoptera: Coccinellidae). Int. J. Trop. Insect Sci. 26: 35-40.

OMKAR \& BIND R.B. 1993: Records of aphid natural enemies complex of Uttar Pradesh (I). The Coccinellids. J. Adv. Zool. 14: 96-99.

OMKAR \& Bind R.B. 2004: Prey quality dependent growth, development and reproduction of a biocontrol agent, Cheilomenes sexmaculata (Fabricius) (Coleoptera: Coccinellidae). Biocontr. Sci. Technol. 14: 665-673.

OMKAR \& JAMES B.E. 2004: Influence of prey species on immature, survival, development, predation and reproduction of Coccinella transversalis Fabricius (Coleoptera: Coccinellidae). J. Appl. Entomol. 128: 150-157. 
OMKar \& Mishra G. 2005: Preference-performance of a generalist predatory ladybird: A laboratory study. Biol. Contr. 34: 187-195.

OmKar \& SRIVAStava S. 2003: Influence of six aphid prey species on development and reproduction of a ladybird beetle, Coccinella septempunctata. BioControl 48: 379-393.

Omkar, Pervez A. \& Singh S.K. 2005: Development and immature survival of two aphidophagous ladybirds, Coelophora biplagiata and Micraspis discolor. Insect Sci. 12: 375-379.

Pervez A. \& Omkar 2004: Prey dependent life attributes of an aphidophagous ladybird beetle, Propylea dissecta (Coleoptera: Coccinellidae). Biocontr. Sci. Technol. 14: 385-396.

Ponsonby D. \& Copland M.J.W. 1998: Environmental influences on fecundity, egg viability and egg cannibalism in the scale insect predator Chilocorus nigritus. BioControl 43: $39-52$.

Puttarudriah M. \& Channabasavanna G.P. 1953: Beneficial coccinellids of Mysore I. Indian J. Entomol. 15: 87-95.

Ramani S., Poorani J. \& Bhumannavar B.S. 2002: Spiralling whitefly, Aleurodicus disperses in India. Biocontr. News Inform. 23(2): $55 \mathrm{~N}-62 \mathrm{~N}$.

Rana J.S., Dixon A.F.G. \& JAROŠíK V. 2002: Costs and benefits of prey specialization in a generalist insect predator. J. Anim. Ecol. 71: 15-22.

RHAMALINGHAN M. 1986: Seasonal variation in ovariole numbers / ovary in Coccinella septempunctata L. (Coleoptera: Coccinellidae). Proc. Ind. Natl. Sci. Acad. 52: 619-623.

RotT A.S. \& Ponsonby D.J. 2000: The effects of temperature, relative humidity and host plant on the behaviour of Stethorus punctillum as a predator of the two-spotted spider mite, Tetranychus urticae. BioControl 45: 155-164.
Singh V.S., Yadav R.R. \& Singh R. 1994: Post embryonic development, survival rate and predation potential of Coccinella septempunctata Linn. in relation to the mustard aphid (Lipaphis erysimi Kalt.). J. Entomol. Res. 18: 5-10.

Soares A.O., Coderre D. \& Schanderl H. 2005: Influence of prey quality on the fitness of two phenotypes of Harmonia axyridis adults. Entomol. Exp. Appl. 114: 227-232.

Stamp N.E. \& Meyerhoefer B. 2004: Effects of prey quality on social wasps when given a choice of prey. Entomol. Exp. Appl. 110: 45-51.

Sugiura K. \& TAKada H. 1998: Suitability of seven aphid species as prey of Cheilomenes sexmaculata (F.) (Coleoptera: Coccinellidae). Jap. J. Appl. Entomol. Zool. 42: 7-14.

SundaraRaj R. 2008: Distribution of predatory arthropod communities in selected sandal provenances of South India. $J$. Biopest. 1: 86-91.

Tallamy D.W. \& Denno R.F. 1982: Life history trade-offs in Gargaphia solani (Hemiptera: Tingidae): The cost of reproduction. Ecology 63: 616-620.

VoHLAND K. 1996: The influence of plant structure on searching behaviour in the ladybird, Scymnus nigrinus (Coleoptera: Coccinellidae). Eur. J. Entomol. 93: 151-160.

Williams L., Morra M.J., Brown P.D. \& McCaffrey J.P. 1993: Toxicity of allyl isothiocyanate-amended soil to Limonius californicus (Mann.) (Coleoptera: Elateridae) wireworms. $J$. Chem. Ecol. 19: 1033-1046.

Zalavadia A.G. \& Kapadia M.N. 2000: Comparative Predation Capacity of Coccinella septempunctata L. on Three Prey Aphids. 7th National Symposium on Aphidology. DDU Gorakhpur University, Gorakhpur, 49 pp.

Received May 5, 2009; revised and accepted July 3, 2009 